\title{
Racking Performance of Poplar Laminated Veneer Lumber Frames and Frame-shear Hybrid Walls
}

\author{
Yan Liu, ${ }^{\mathrm{a}}$ Zizhen Gao, ${ }^{\mathrm{b}}$ Hong-wei Ma, ${ }^{\mathrm{a}, *}$ Meng Gong, ${ }^{\mathrm{b}}$ and Honghe Wang ${ }^{\mathrm{a}}$ \\ This study examined the racking performance of poplar laminated veneer \\ lumber (LVL) frames using bolted steel filling plates to connect beam- \\ column joints, poplar LVL frames using the embedment bars to connect \\ beam-column joints, and frame-shear hybrid walls made of poplar LVL \\ studs and oriented strand board (OSB) sheathing panels. A new design \\ load spreader beam was used on the side of the top of a specimen to apply \\ monotonic and cyclic loadings. It was found that the lateral force \\ resistance, stiffness, and ultimate loads of poplar LVL pure frames with \\ bolted steel filling plate connections and closed rod connections were \\ much lower than those of the poplar LVL frame-shear wall hybrid structure. \\ The highest initial stiffness of the poplar LVL hybrid frame-shear wall was \\ $1.77 \mathrm{kN} / \mathrm{mm}$, which was $24 \%$ and $22 \%$ lower than that of the conventional \\ shear wall made with spruce-pine-fir studs and OSB or plywood sheathing \\ panels, respectively. The poplar LVL frame-shear wall hybrid structure \\ showed lower degradation in stiffness than the conventional shear wall. \\ The hybrid frame-shear wall structures made of poplar LVL could meet the \\ requirements of Chinese standard; however, diagonal braces were \\ required in use of poplar LVL pure frames.
}

Keywords: Poplar LVL; Frame; Frame-shear wall; Load spreader beam; Racking performance

Contact information: a: College of Civil Science and Engineering, Yangzhou University, Yangzhou, Jiangsu 225127, China; b: Wood Science and Technology Center, University of New Brunswick, Fredericton, New Brunswick, E3C 2G6, Canada; *Corresponding author: hwma@yzu.edu.cn

\section{INTRODUCTION}

Timber frame structures are common construction systems for low-rise residential houses, commercial buildings, and industrial structures in North America and Northern Europe. Modern frame timber buildings have good performance when subjected to horizontal actions, such as wind or seismic loads, as the lateral forces are transferred from the horizontal diaphragms to the vertical bracing systems and then to the foundation (Gattesco and Boem 2016). Wood has been used for thousands of years in China. However, due to the decline in China's forest resources, few modern, heavy-wood-frame buildings have been built in the last several years. Therefore, it is essential to find new materials and products made in China to construct modern frame timber buildings.

In the 1960s and 1970s, China successfully introduced poplar (Populus euramericana cv. I-214) from Italy, and it has become popular in China. After decades of development, the domestic poplar resources are quite rich, and many wood products, such as laminated veneer lumber (LVL), are manufactured from domestic poplar and widely used as packing materials and furniture components in China. However, they are seldom used in building construction. Limited research has been conducted on the racking behavior of LVL frames, despite their extensive use in traditional Chinese wood construction. Racking behavior is the structural performance such as displacement, stiffness, and energy 
consumption of a specimen when subjected to lateral (racking) loading, in particular under the low-cycle fatigue loading. This study was undertaken to address the gap.

Timber framed panel walls are load-resisting elements composed of two main components: timber frame elements and sheathing materials such as oriented strand board (OSB) (Thelandersson and Larsen 2003; Premrov and Kuhta 2011). In addition, the connection types are one of the main factors that affect the racking behavior of wood frames. In recent years, many researchers have studied the mechanical properties of wood frames, such as their racking behavior. Komatsu (2004) first evaluated the shear performance of frame structures without any wall elements and then evaluated small prefabricated mud shear walls (PMSWs). The small prefabricated mud components were inserted into the frames to increase shear resistance under static push-pull cyclic lateral shear testing. Five different types of shear wall configurations were prepared and examined. It was found that an increase of stiffness of the wall system was approximately proportional to the number of mud blocks (Komatsu 2004). Shim et al. (2010) studied the lateral load resistance of hybrid structures under cyclic lateral load. They tested five types of wall systems in quasi-static reversed-cyclic load and found that the hybrid wall structures with both column and beam and light frame shear wall could resist higher lateral load than the light frame shear wall. The lateral load resistance of the hybrid wall was an arithmetic summation of the column and beam structure and the light frame shear wall. The hybrid wall with an opening had lower stiffness and lateral load resistance than the hybrid solid wall. The initial stiffness of the hybrid wall with a window opening was small, and as the lateral load increased, the lateral load resistance of the wall increased at the level of the hybrid solid wall (Shim et al. 2010). Suzuki and Maeno (2013) evaluated the seismic performance of traditional wood frames from shaking table tests and static tests using several scale models. They found that the horizontal restoring force of the wooden frame without walls depended mainly on the bending moment resistance from tie beams and the restoring force due to column rocking. When frame deformation was small, a major part of the total restoring force was the restoring force due to column rocking. The bending moments from tie beams became dominant as the deformation increased, and the traditional wooden frame had large flexibility and deformability. Erikson (2003) investigated the effects of lateral load on the stiffness of full-scale timber frames, in which wood columns and beams were connected with wood pegs. One-story, one-bay frames and two-story, twobay frames made of various wood species were tested in both unsheathed and sheathed conditions and modeled with a structural analysis program. Load-slip characteristics were analyzed for single-fastener SIP (structural insulated panels)-to-timber connections. Excessive displacements of the frames indicated an unacceptable flexibility when subjected to reversible lateral loads, and the knee brace system provided exceptional strength characteristics due to the substantial available compressive action of the joints. Further, the use of SIP sheathing improved frame stiffness to a large degree (Erikson 2003). Lam et al. (2008) investigated the contribution of self-tapping screws as perpendicular-tograin reinforcements for bolted glue-laminated timber connections with slotted-in steel plates. The test results from the beam-to-column connection specimens showed that the connections reinforced with self-tapping screws had increased capacities by a factor of 2 and 1.7 when compared to un-reinforced connections under monotonic and reversed cyclic loading, respectively (Lam et al. 2008). Schwendner et al. (2018) compared the loadbearing characteristics under cyclic loading of light-frame walls with gypsum fibreboard sheathing and oriented strand board sheathing, respectively. The results indicated that light- 
frame walls with OSB and gypsum fiberboards as sheathing materials had similar behaviour.

This study aimed to investigate the racking performance of poplar LVL frames and frame-shear walls to verify the feasibility of using poplar LVL to fabricate frame-shear wall hybrid structures and provide a theoretical basis for the design and application of LVL structures.

\section{EXPERIMENTAL}

\section{Design of Specimens}

The specimens were designed according to the requirements specified by Chinese standards (Editorial Committee of the Wood Structure Design Manual 2005; GB 50005 2017). The LVL pieces made of poplar (Populus euramericana cv. I-214) were purchased from Siyang Jiuhe Wood Industry Co. Ltd., Siyang, Jiangsu, China and used to fabricate three kinds of frames, which included two types of pure beam-column frame specimens (KJ1 and KJ2) and one type of frame-shear wall specimens (KJ3). The properties of the LVL are shown in Table 1 (Liu et al. 2017). According to Table 1, the mechanical properties of poplar LVL were similar to SPF lumbers. The frames of the three types were designed with the same dimensions, namely $2.55 \mathrm{~m}$ in height and $2.3 \mathrm{~m}$ in width. Each beam had a $75 \mathrm{~mm} \times 150 \mathrm{~mm}$ cross-section, and each column had a $150 \mathrm{~mm} \times 150 \mathrm{~mm}$ cross-section. The panel in the frame-shear wall (KJ-3) was 9.5-mm-thick, 1.2-m-wide, and 2.4-m-tall OSB board.

Table 1. Physical and Mechanical Parameters of Poplar LVL

\begin{tabular}{|c|c|c|c|c|c|c|c|c|c|}
\hline$W(\%)$ & $\rho\left(\mathrm{g} / \mathrm{cm}^{3}\right)$ & $E_{1}(\mathrm{MPa})$ & $E_{2}(\mathrm{MPa})$ & $E_{3}(\mathrm{MPa})$ & $E_{4}(\mathrm{MPa})$ & $P_{1}(\mathrm{MPa})$ & $P_{2}(\mathrm{MPa})$ & $P_{3}(\mathrm{MPa})$ & $P_{4}(\mathrm{MPa})$ \\
\hline 13.1 & 0.570 & 11,073 & 1630 & 602 & 9720 & 27.8 & 10.4 & 4.3 & 39.4 \\
\hline $\begin{array}{l}\text { Note: } \\
\text { is the } \\
\text { radial } \\
\text { of elas } \\
\text { directi } \\
\text { transv }\end{array}$ & $\begin{array}{l}V \text { is the a } \\
\text { nodulus } \mathrm{c} \\
\text { lirection; } \\
\text { icity in th } \\
\mathrm{n} ; P_{2} \text { is } \mathrm{t} \\
\text { rse grain }\end{array}$ & $\begin{array}{l}\text { corallel- } \\
\text { compre } \\
\text { mpress }\end{array}$ & $\begin{array}{l}\text { odulus o } \\
\text { o-grain c } \\
\text { ssive stre } \\
\text { ive stren }\end{array}$ & $\begin{array}{l}\text { rection; } \\
\text { ngth in th } \\
\text { th; } P_{4} \text { is }\end{array}$ & e tensile & parallel-to & the para & $\begin{array}{l}\text { the parall } \\
\text { ection; } P_{3} \text { is } \\
\text { l-to-grain }\end{array}$ & $\begin{array}{l}\text { ar LVL; } E_{1} \\
\text { ty in the } \\
\text { e modulus } \\
\text { el-to-grain } \\
\text { s the } \\
\text { direction }\end{array}$ \\
\hline
\end{tabular}

The $\mathrm{KJ} 1$ and $\mathrm{KJ} 2$ beam and column joint specimens were fabricated with bolted steel filling plates and rods, respectively. The connections of the beam and column joints for KJ3 were the same as those of KJ1. As shown in Figs. 1 and 2, 8-mm-thick Q235 steel plates and bolts with a nominal diameter of $8 \mathrm{~mm}$ and a strength of 8.8 grade were used to make bolted steel filling plate connections. Ten-mm-thick Q235 steel plates and bolts with a nominal diameter of $14 \mathrm{~mm}$ and a strength of 8.8 grade, as shown in Figs. 3 and 4, were adopted for the bolted steel filling plate connections at the LVL column foot. The rod connections of the beams and columns of specimen KJ2 are shown in Figs. 5 and 6. A threaded rod of $12 \mathrm{~mm}$ in diameter and a strength of 8.8 grade was used. The penetration depth of rods used should be greater than 15 times the diameter of the rods used to avoid brittle pulling-out failure. The penetration depth was $200 \mathrm{~mm}$. 


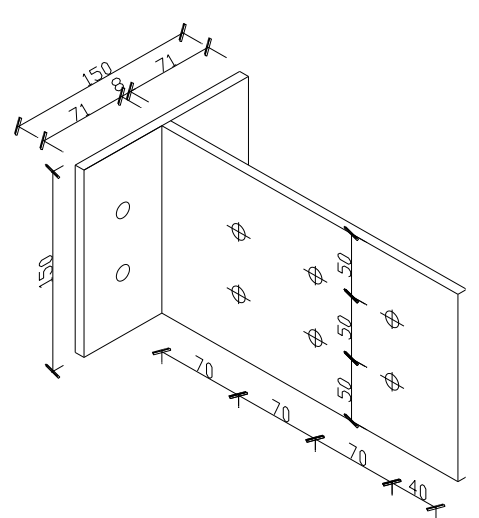

Fig. 1. Elevation of the steel filling plate

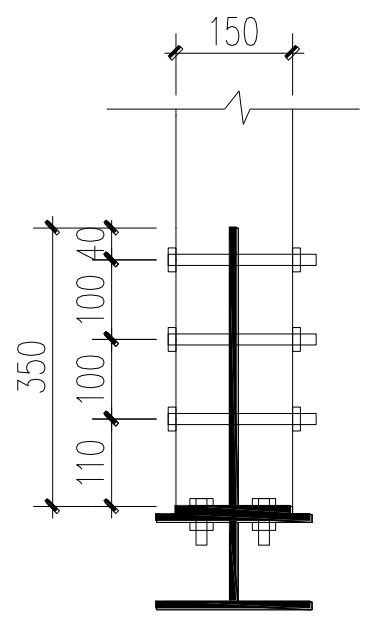

Fig. 3. Profile of the column base joints filling plate

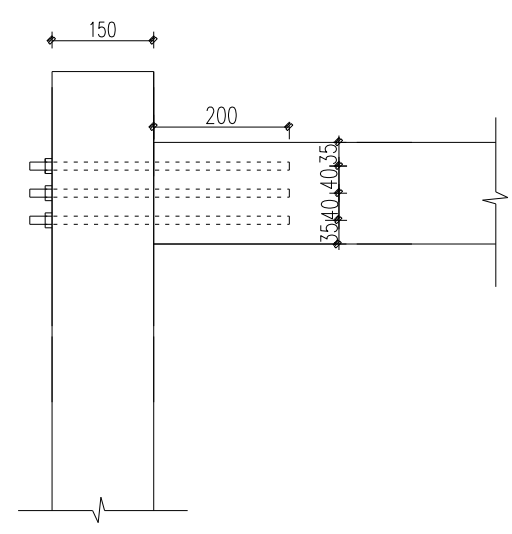

Fig. 5. Facades of the planting bar joints

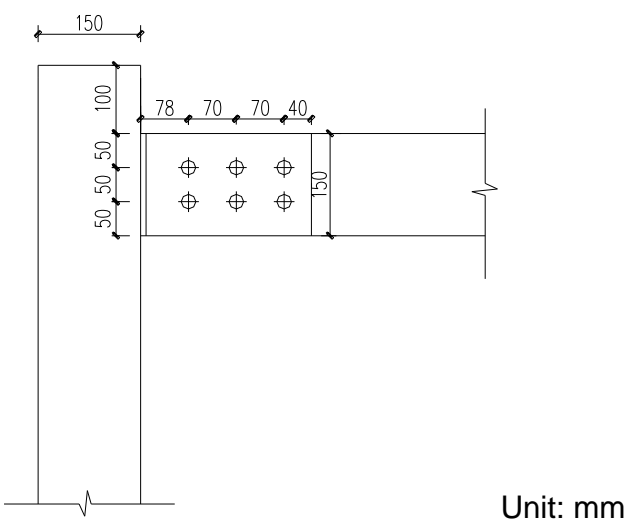

Fig. 2. Axonometrical drawing of the steel filling plate

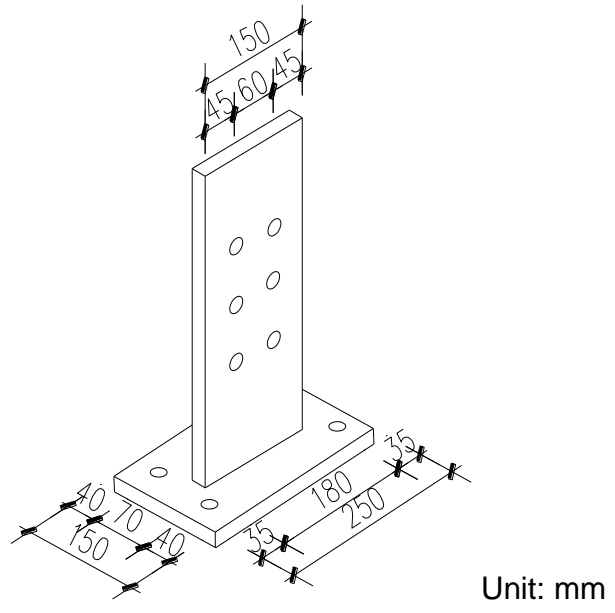

Fig. 4. Axonometrical drawing of the column steel

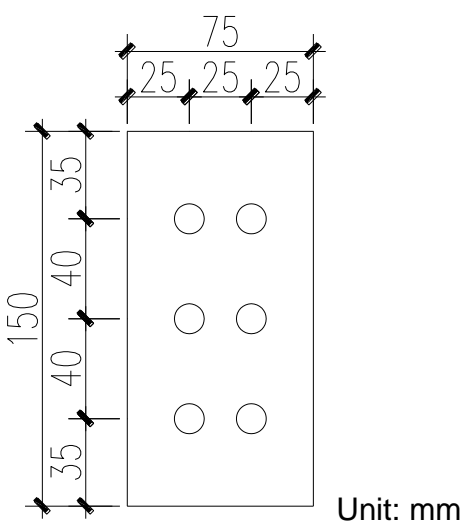

Fig. 6. Position site of the planting joints

For the racking resistance test, three types of specimens (KJ1, KJ2, and $\mathrm{KJ} 3$ ) were used. Each group had two specimens, which resulted in a total of six specimens, namely KJ1-a, KJ1-b, KJ2-a, KJ2-b, KJ3-a, and KJ3-b, where "a" denotes the specimen used for the monotonic load test, and " $b$ " denotes the specimen used for the cycle load test. The specimens are illustrated in Figs. 7, 8, and 9. 


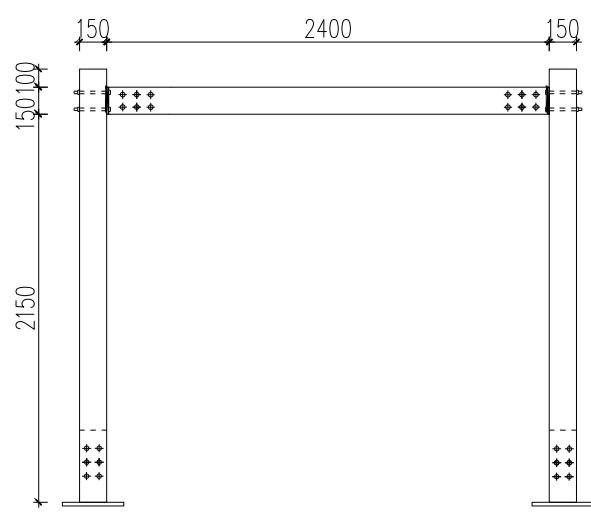

(a)

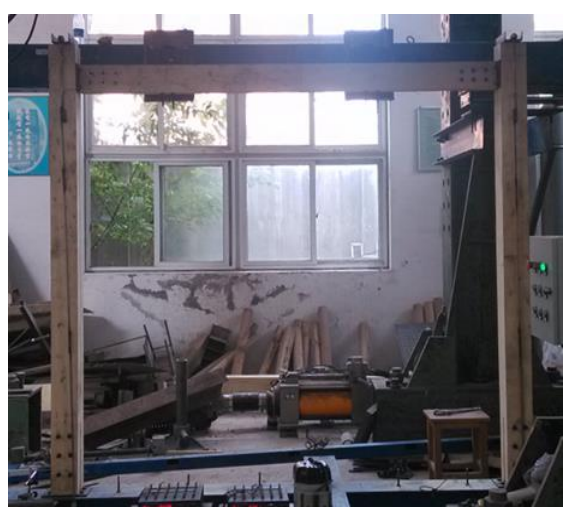

(b)

Fig. 7. Steel filling plate bolt connection of LVL frame KJ1: (a) Design; (b) Photo

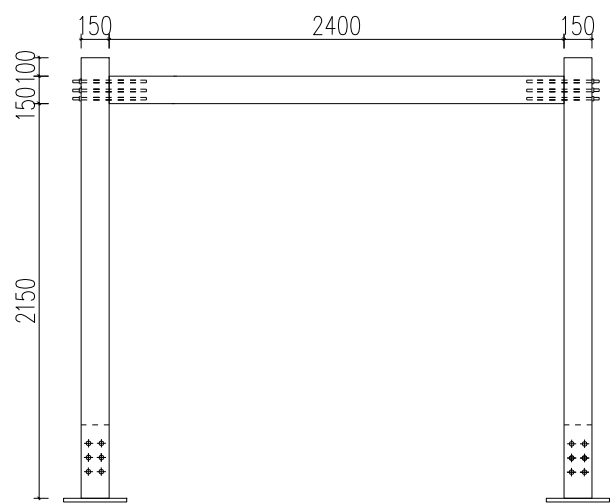

(a)

Fig. 8. Rod joint connection of LVL frame KJ2: (a) Design; (b) Photo

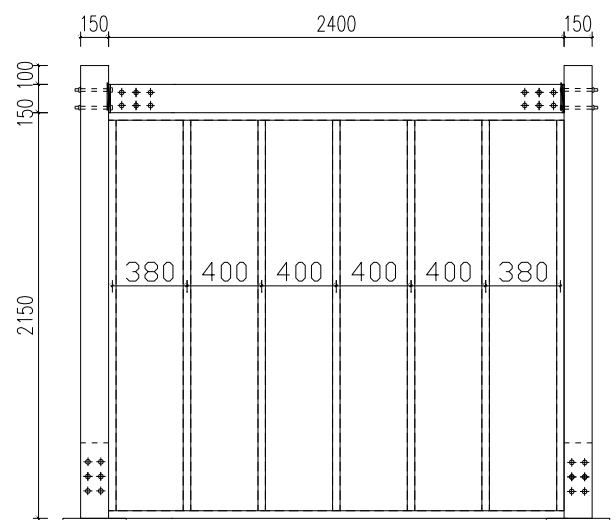

(a)

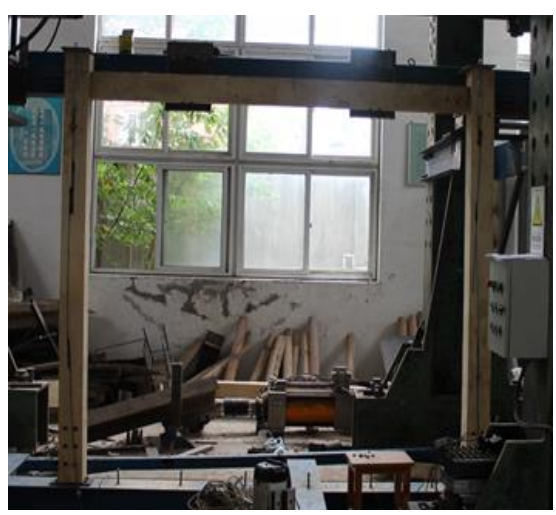

(b)

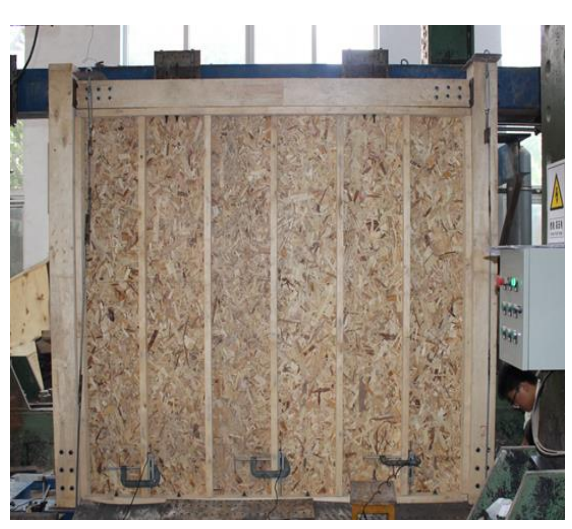

(b)

Fig. 9. Frame with frame-shear wall hybrid structure KJ3: (a) Design; (b) Photo

\section{Testing Setup}

A novel lateral horizontal loading device developed by Liu et al. (2008) was used, which was available at the Structural Laboratory, Yangzhou University, Yangzhou, China. This device kept the applied load unchanged due to the load head at the lateral edge. The load head shifted along with and to offset the shifting of the specimen caused by the action of lateral force, as shown in Fig. 10. The novel loading beam does not restrict the lateral 
and vertical movements of a specimen subjected to the lateral loading, and it can also ensure the effective transferring of lateral loads.

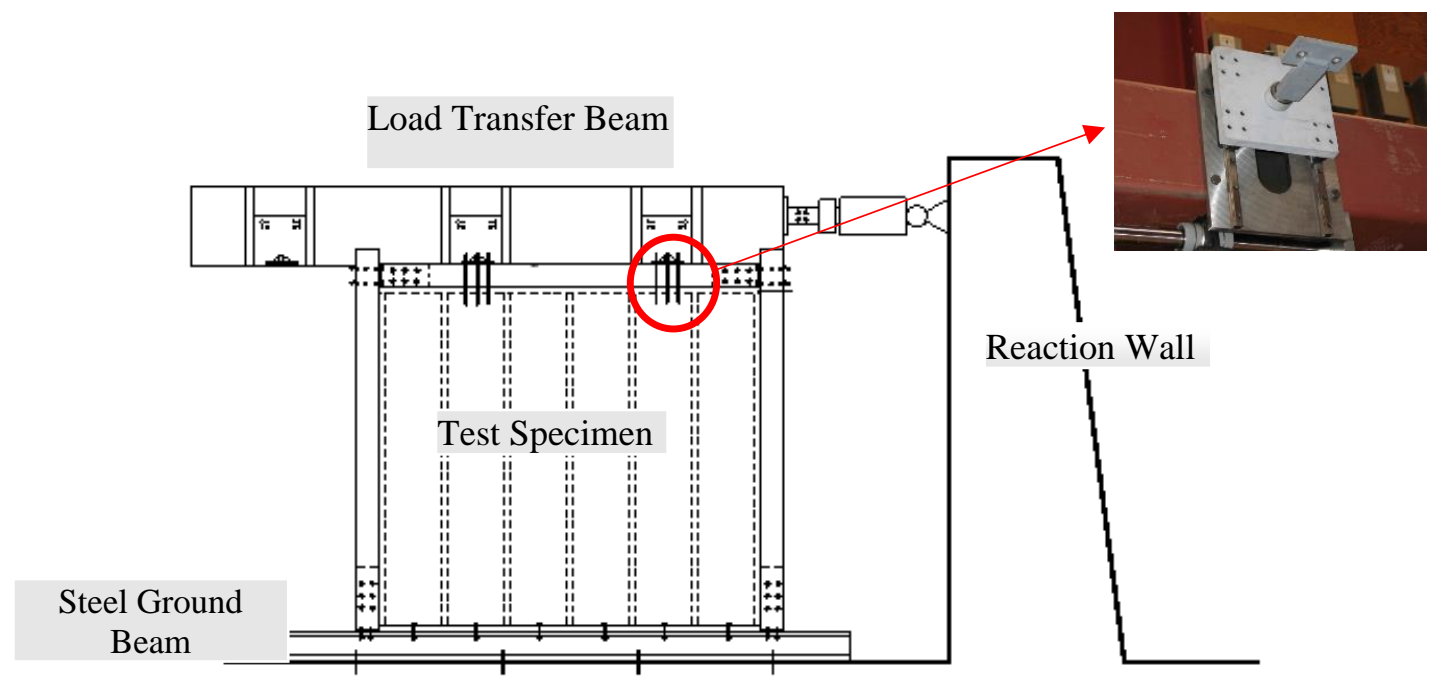

Fig. 10. Experimental setup for testing a wall

\section{Arrangement of LVDTs}

For the pure LVL frame specimens (KJ1 and $\mathrm{KJ} 2$ ), two linear variable differential transducers (LVDTs) ( $\mathrm{V}_{1}$ and $\mathrm{V}_{2}$ ) were mounted at the column foot, and two LVDTs $\left(\mathrm{V}_{3}\right.$ and $\mathrm{V}_{4}$ ) were installed at the axis points at both ends of the beam. For the timber frameshear wall hybrid structure specimens (KJ3), in addition to the four LVDTs ( $V_{1}, V_{2}, V_{3}$, and $\left.\mathrm{V}_{4}\right)$ arranged at the column bottom and beam ends, three additional LVDTs $\left(\mathrm{V}_{5}, \mathrm{~V}_{6}\right.$, and $\mathrm{V}_{7}$ ) were installed on the longitudinal wall bottom beam plate to measure the vertical relative displacement between the stud and steel foundation beam. To optimize the test and analyze the global and local deformation properties of the specimens, a dial indicator was also placed on the frame to measure the displacement of the specimen stud relative to both the top and bottom beam plates and the rotation angle relative to the frame. Figure 11 illustrates the detailed arrangement of the LVDTs $\left(\mathrm{V}_{1}\right.$ to $\left.\mathrm{V}_{7}\right)$.

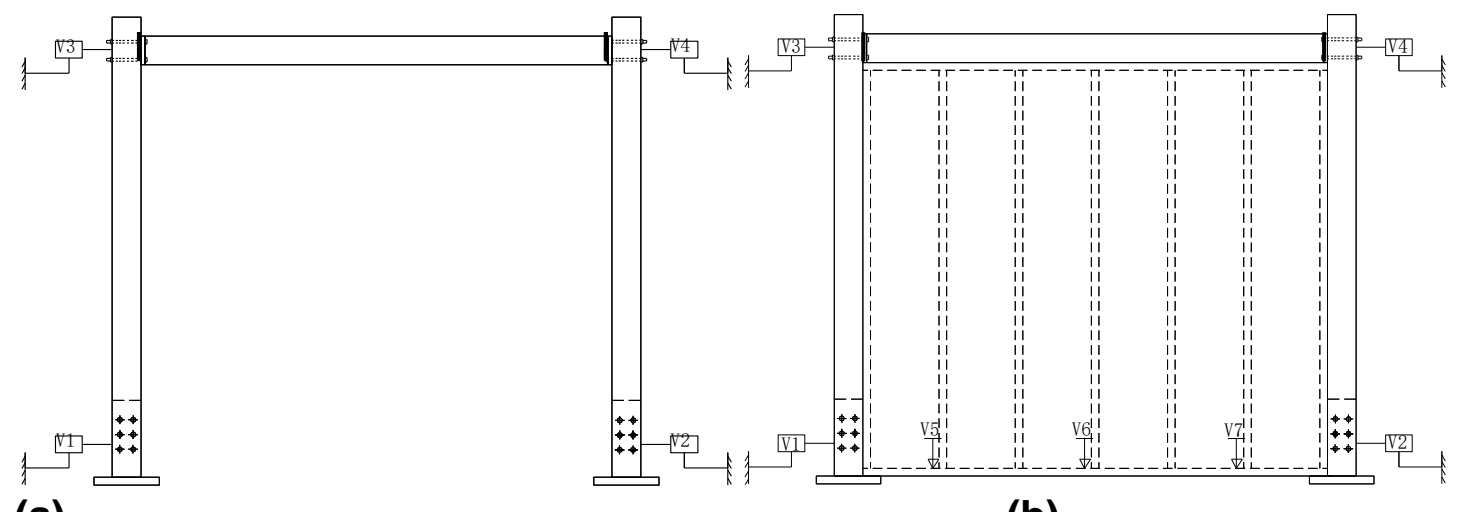

(a)

(b)

Fig. 11. Test point layout: (a) layout of the pure frame measurement points; (b) Wood frameshear wall measuring point layout 


\section{Loading Scheme}

The loading procedure specified by ISO-16670 (2003) and the displacement control loading procedures specified by ASTM E2126 (2009) were adopted for this study. The low-cycle reversed loading tests were conducted on all three groups, as shown in Table 2. The loading rate of the unidirectional loading test was $7.5 \mathrm{~mm} / \mathrm{min}$, and that of the reversed loading test was $3 \mathrm{~mm} / \mathrm{s}$. The relative deformations of the pure frame specimens (KJ1 and $\mathrm{KJ} 2$ ) became too large when they reached $200 \mathrm{~mm}$ with the subsequent termination of loading. Thus, the corresponding load at this displacement was defined as the ultimate load.

Table 2. Load Test Loading Scheme

\begin{tabular}{|c|c|c|c|c|c|c|c|c|c|c|c|}
\hline Step & 1 & 2 & 3 & 4 & 5 & 6 & 7 & 8 & 9 & 10 & 11 \\
\hline Cycles & 1 & 1 & 1 & 1 & 1 & 3 & 3 & 3 & 3 & 3 & 3 \\
\hline$\Delta_{\mathrm{p}} / \Delta_{\mathrm{e}}$ & $1.25 \%$ & $2.5 \%$ & $5 \%$ & $7.5 \%$ & $10 \%$ & $20 \%$ & $40 \%$ & $60 \%$ & $80 \%$ & $100 \%$ & $120 \%$ \\
\hline
\end{tabular}

Note: $\Delta_{\mathrm{p}}$ is the peak displacement of the cyclic loading curve, and $\Delta_{\mathrm{e}}$ is the ultimate displacement determined by the monotonic loading test

\section{Calculations}

Stiffness degradation

The degradation in stiffness fully reflected the occurrence and propagation of the cracks in members and the development of plastic deformation in members due to the cumulative effects of structural damage under the reversed load. The stiffness of a specimen is usually expressed in the secant stiffness $K$, which is calculated with Eq. 1,

$$
K_{i}=\frac{\left|+Q_{i}\right|+\left|-Q_{i}\right|}{\left|+\Delta_{i}\right|+\left|-\Delta_{i}\right|}
$$

where $Q_{\mathrm{i}}$ indicates the peak load at time $i$, and $\Delta_{\mathrm{i}}$ indicates the peak displacement at time $i$.

\section{Energy dissipating capacity}

The energy dissipating capacity of a specimen can be expressed by the equivalent viscous damping coefficient $\xi_{\text {eq }}$. The plumpness of the hysteresis curve of a specimen was positively correlated to the equivalent viscous damping coefficient $\xi_{\mathrm{eq}}$, and they increased together to form a higher energy dissipating capacity. The equivalent viscous damping coefficient $\left(\xi_{\mathrm{eq}}\right)$ can be calculated with Eq. 2,

$$
\xi_{e q}=\frac{E}{2 \pi}
$$

where $E$ is the energy dissipating coefficient, which can be calculated by using Eq. 3, according to JGT/T 101 (2015),

$$
E=\frac{S_{A B C}+C D A}{S_{O B E+O D F}}
$$

where $S_{\mathrm{ABC}+\mathrm{CDA}}$ is the area enclosed by the hysteresis curve in one cycle (i.e., the energy dissipated), and SOBE + ODF is the area enclosed by the hypothetical elastic line DB and the coordinate axis of displacement. The equivalent viscous damping coefficient is shown in Fig. 12. 


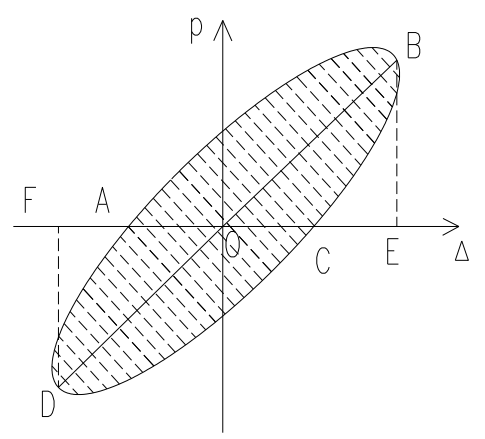

Fig. 12. Calculation of the equivalent viscous damping coefficient

\section{RESULTS AND DISGUSSION}

\section{Tests Phenomena}

During the monotonic loading test, the column bottom bolts and bolted steel filling plate connections continuously generated cracking sounds as the horizontal displacement rate decreased and they were squeezed into the timber. The failure of a specimen was initiated near the column bottom bolt holes; splitting occurred along the height of the poplar LVL column. Further, splitting cracks appeared at the column bottom of the bolted steel filling plate connection frame (KJ1-a) and the penetrated bar connection frame (KJ2-a) when the displacements reached $60 \mathrm{~mm}$ and $50 \mathrm{~mm}$, respectively. Such splitting cracks at the column bottom extended but did not pass through the bolt holes as horizontal displacement increased. Figure 13 shows the failure observed in specimen KJ1-a.

Specimens KJ-1b and KJ-2b were still in the stage of elasticity due to the range of the actuator under the low cyclic repeated loading, and there was no failure.

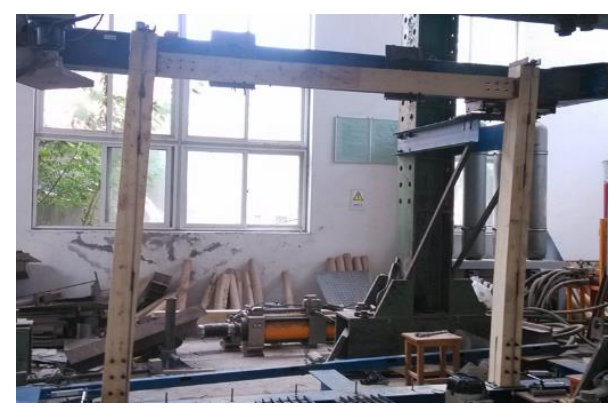

(a)

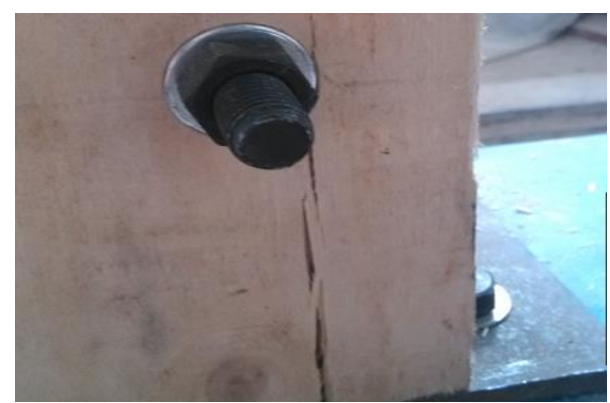

(b)

Fig. 13. Failure of KJ1-a: (a) Lateral deformation of KJ1-a; (b) Column foot splits and breakages of $\mathrm{KJ} 1-\mathrm{a}$

As specimen $\mathrm{KJ} 3$-a was monotonically loaded, dislocations occurred at the splicing joints between the panels when the load reached $32 \mathrm{~mm}$. As displacement increased, crushing was found at the wall panel bottom, and the nails were pulled out at the panel splicing joints. Additionally, outward warping was found in the OSB panels, which were separated from the studs to the right of the splicing joints. Throughout the test, stud $\mathrm{V}_{6}$ at the middle of the timber shear wall was obviously pulled up more than the other studs, whereas the studs at both ends were not pulled up substantially. In this process, no obvious 
failure was observed at the beam or column ends of the LVL frame. When the LVL frame shear wall failed, the frame remained in good condition with a certain bearing capacity. For KJ3-a specimen, the stiffness was greatly increased since the OSB panels was used. As shown in Fig. 14, the main failure of KJ3-a occurred at the joints between the sheathing and studs, in which the specimens were considered being failed. Since the KJ1-a and KJ2a specimens did not have sheathing and middle studs, the displacement to lead to failure of the joint between the post and beam were much larger than that of sheathing and studs. According to the standards, the specimens were considered as having failed when the displacement reached $200 \mathrm{~mm}$. In this case, the KJ1-a and KJ2-a specimens during testing were stopped when the displacement reached $200 \mathrm{~mm}$ although they did not collapse.

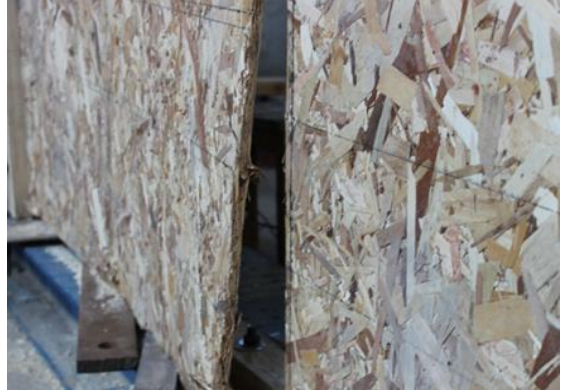

(a)

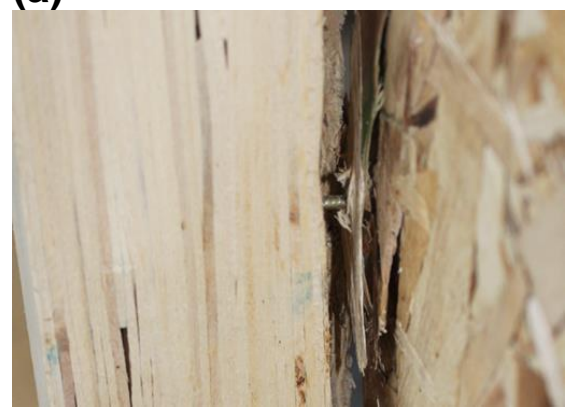

(c)

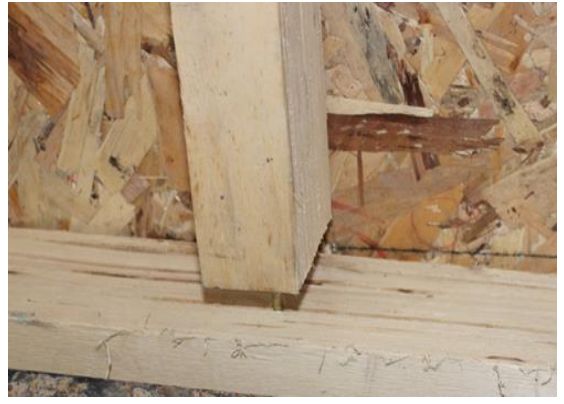

(e)

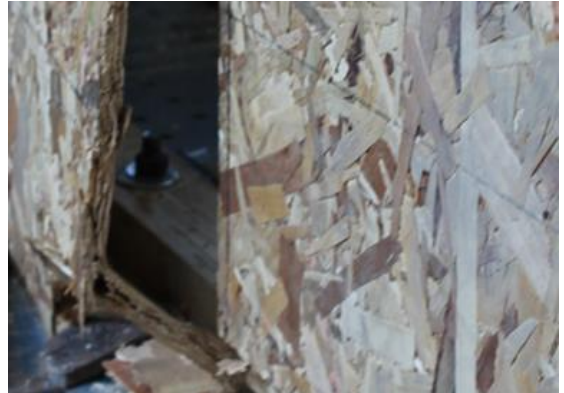

(b)

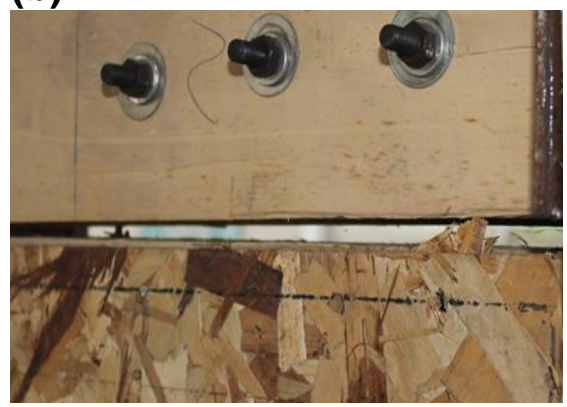

(d)

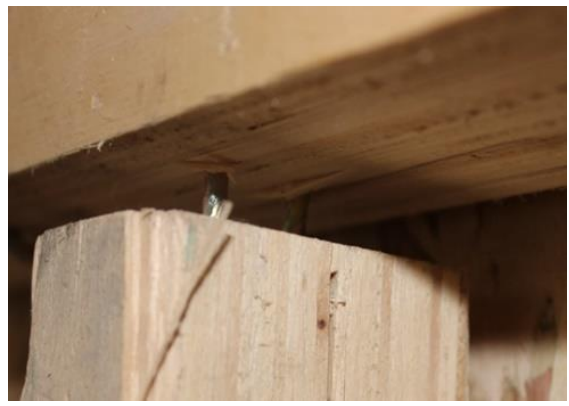

(f)

Fig. 14. Sample KJ3-b test: (a) and (b) panel torn apart; (c) nail piercing panel; (d) top beam detached from the frame beam; (e) the column detached from the wall; (f) the wall separated from the top beam

When KJ3-b was subjected to the low-cycle reversed load, dense sounds were audible throughout the test. When the displacement reached $30 \mathrm{~mm}$, dislocations occurred between the OSB panels. As displacement increased, the nails at the panel side gradually penetrated the OSB panels and were pulled out. During loading, all studs were pulled up, 
and the middle stud was pulled up most obviously. The lower end of the stud close to the loading end was also pulled up noticeably, whereas the studs at the upper end did not separate from the frame substantially. The lower ends of the two studs far from the loading end were not pulled up visibly, but the upper ends clearly disengaged from the frame. Outward warps were found on the OSB panels close to the loading end, and the nails at the sides penetrated the OSB panels. The nails at the joints between the LVL frame beams and the LVL shear wall were pulled out. The nails at the joints between the LVL frame columns and the studs in LVL shear wall were not pulled out. The damage phenomenon of KJ3-b is shown in Fig. 14. According to the results of Shenton's (1998) study, the failure modes of SPF shear wall with OSB sheathing, characterized by fatiguing of the exterior sheathing nails which eventually broke off or were pulled from the frame and a cracking sound, which the damage patterns and failure modes were similar to that of KJ3-a specimens in this study.

\section{Monotonic Loading Tests}

Table 3 summarizes the bearing capacities, displacement, stiffness, and energy dissipating values of all three specimens.

Table 3. Test Date of Each of the Three Types of Specimens

\begin{tabular}{|c|c|c|c|c|}
\hline Specimen & $\begin{array}{c}\text { Ultimate Load } \\
\left(F_{\text {peak }}\right)(\mathrm{KN})\end{array}$ & $\begin{array}{c}\text { Ultimate Displacement } \\
\left(\triangle \Delta_{\text {peak }}\right)(\mathrm{mm})\end{array}$ & $\begin{array}{c}\text { Stiffness } \\
(\mathrm{KN} / \mathrm{mm})\end{array}$ & $\begin{array}{c}\text { Energy } \\
\text { dissipation } \\
(\mathrm{KN} . \mathrm{mm})\end{array}$ \\
\hline $\mathrm{KJ} 1-\mathrm{a}$ & 13.18 & 199.9 & 0.066 & 1317.34 \\
\hline $\mathrm{KJ} 2-\mathrm{a}$ & 12.16 & 199.6 & 0.061 & 1213.57 \\
\hline $\mathrm{KJ} 3-\mathrm{a}$ & 22.35 & 49.81 & 0.449 & 556.63 \\
\hline $\begin{array}{c}\text { Douglas-fir- } \\
\text { OSB }\end{array}$ & 23.72 & 51.70 & 0.459 & 613.16 \\
\hline
\end{tabular}

Note: The loading was stopped when the relative deformation reached $200 \mathrm{~mm}$ for the pure frame specimens (KJ1 and KJ2)

The ultimate loads of KJ1-a and KJ2-a were 13.2 and $12.2 \mathrm{kN}$, respectively. The ultimate displacements of KJ1-a and KJ2-a were $199.9 \mathrm{~mm}$ and $199.6 \mathrm{~mm}$, respectively. The ultimate bearing capacity of the bolted wood-steel-wood connection in the pure frame (KJ1) was close to that of the embedment steel bar connection in the pure frame (KJ2). The initial stiffness of KJ2-a was, at the initial stage of loading, slightly higher than that of KJ1a. During the middle and later loading stages, the stiffness of KJ2-a decreased gradually, whereas the stiffness of $\mathrm{KJ} 1$-a remained unchanged. The ultimate bearing capacity of KJ2a was higher than that of KJ1-a. The frame-shear wall in the hybrid structure specimen (KJ3) had the highest ultimate load of $22.4 \mathrm{kN}$, which was approximately 1.7 times as large as the ultimate bearing capacity of the poplar LVL bolted wood-steel-wood connection in the pure frame. This may have been due to the frame being enhanced by the lateral force resistant performance of the LVL shear wall and the reduction of the lateral displacement of the LVL shear wall and stud lift-up. The ultimate loads and ultimate displacements of the hybrid structure shear walls with Douglas-fir studs and OSB sheathing panels were reported to be $23.7 \mathrm{kN}$ and $51.7 \mathrm{~mm}$, respectively (White et al. 2010). As shown in Table 3 , the differences in the ultimate loads and ultimate displacements of KJ3 and Douglas-firOSB were under $10 \%$. The load-displacement curves of the three different kinds of specimens tested are shown in Fig. 15. 


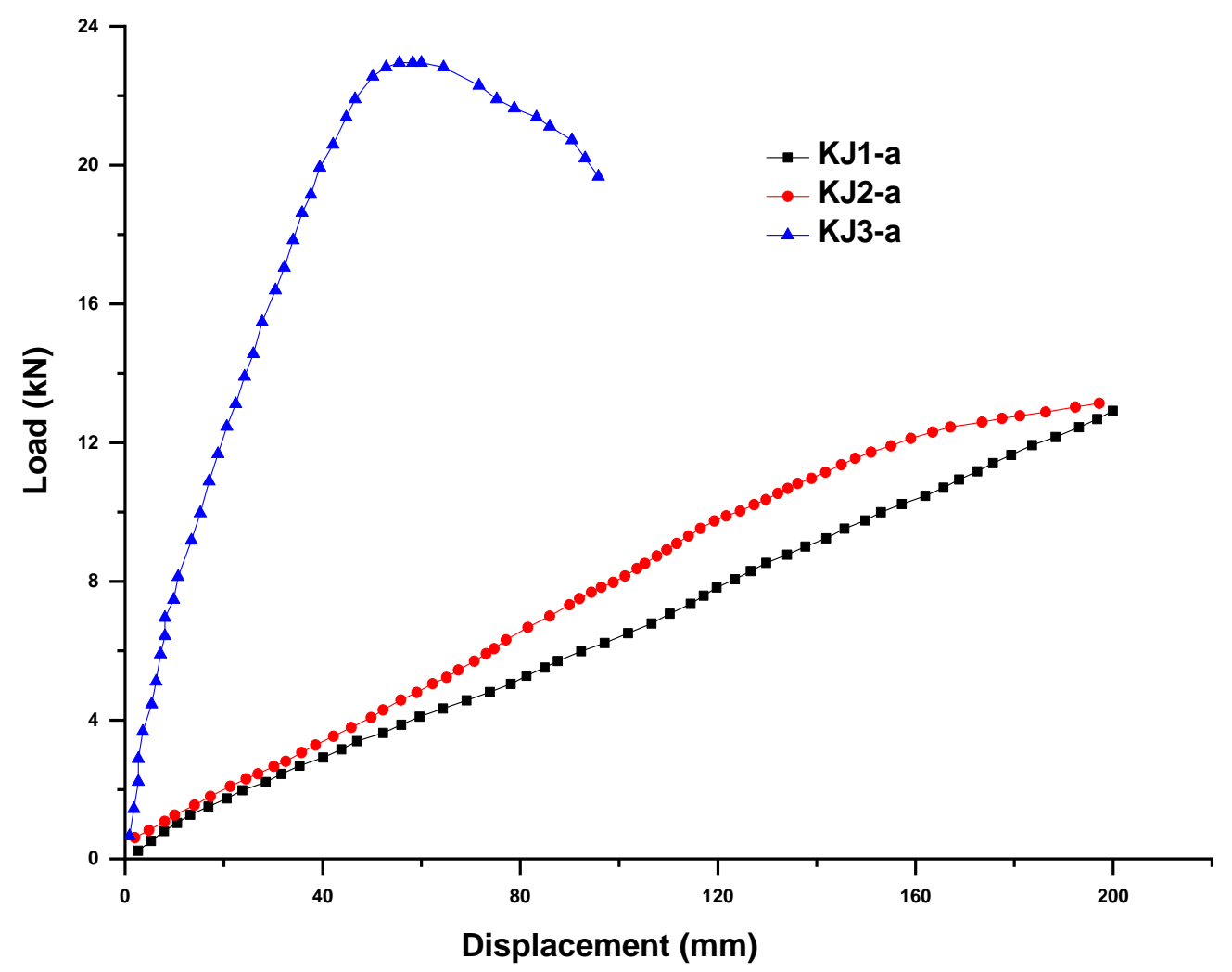

Fig. 15. Load-displacement curves of three types of specimens under monotonical loading

\section{Low-cycle Reversed Loading Tests}

Hysteresis curves

Figure 16 shows the load-displacement curves of all three specimens under lowcycle reversed loading. The loading curves contained inflection points and exhibited an inverse $S$ shape, which was demonstrative of the pinch phenomenon. A greater pinch phenomenon indicates lower ductility and energy dissipating ability. Specimens KJ1-b and $\mathrm{KJ} 2-\mathrm{b}$ had the most obvious pinch effects, whereas specimen KJ3-b had a smaller pinch effect than KJ1-b and KJ2-b. Accordingly, the load in the hysteresis curve of KJ3-b decreased noticeably with cyclic loading, whereas the loads of KJ1-b and KJ2-b still increased after the actuator reached the maximum range of measurement due to their low lateral stiffness. The ultimate lateral displacements of specimens KJ1-b and KJ2-b were approximately 3 to 4 times larger than that of specimen KJ3-b. For KJ1-b and KJ2-b, no obvious decreases in load were observed during the first and second stages. This could have been due to the low stiffness and large ultimate displacements among the pure frame specimens of KJ1-b and KJ2-b. Furthermore, the pure frame specimens of KJ1-b and KJ2$\mathrm{b}$ had increases in their loads as displacement increased. For KJ3-b in the second stage of cycling, the bearing capacity decreased during cycling at the same displacement, and the peak bearing capacity decreased visibly. This decrease signified that the cyclic loading process caused structural damage to this specimen, which resulted in strength degradation. The curve slopes of the last two cycles were lower than that of the first cycle due to the degradation of stiffness in the specimen after the reversed cyclic loads. 


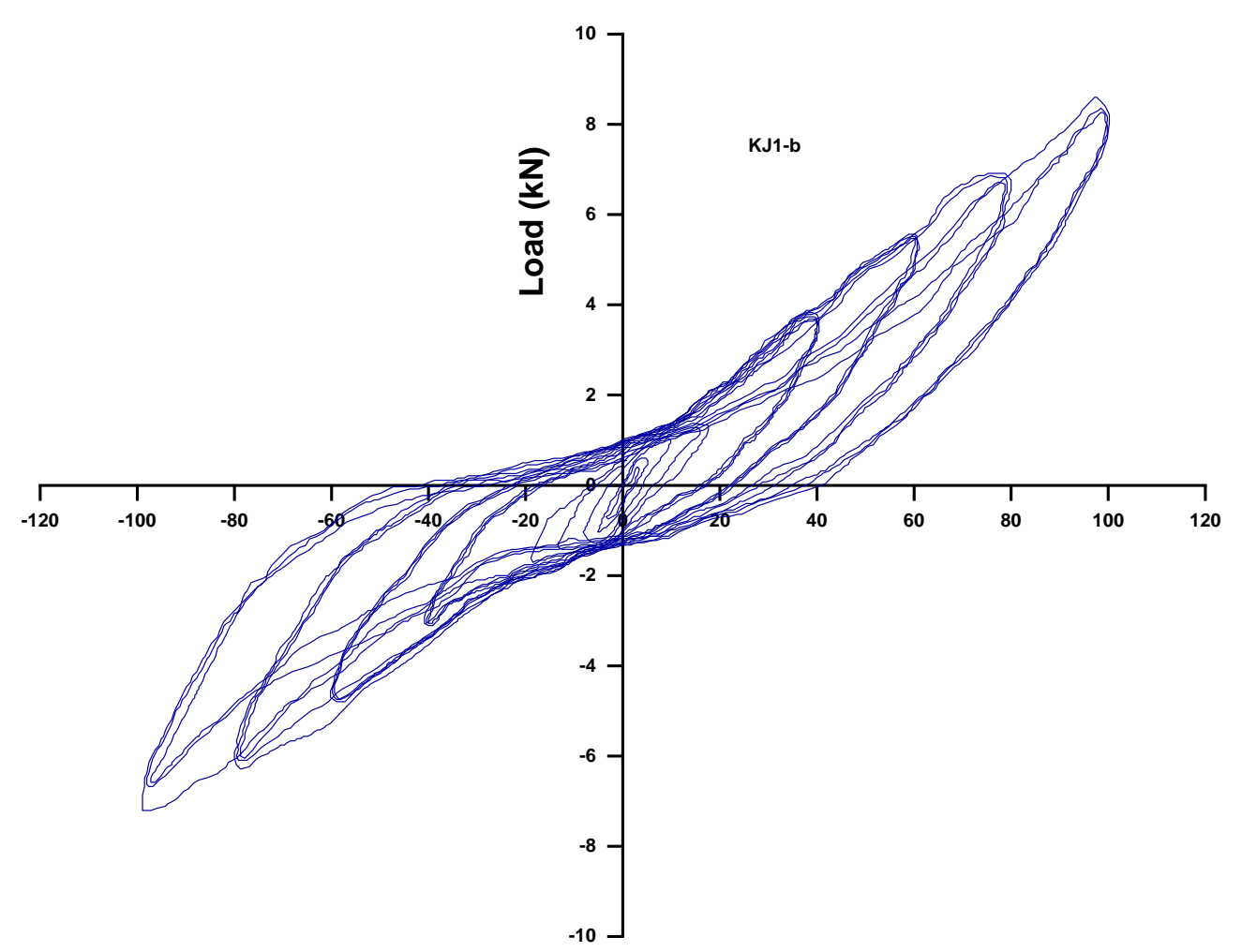

Displacement (mm)

(a)

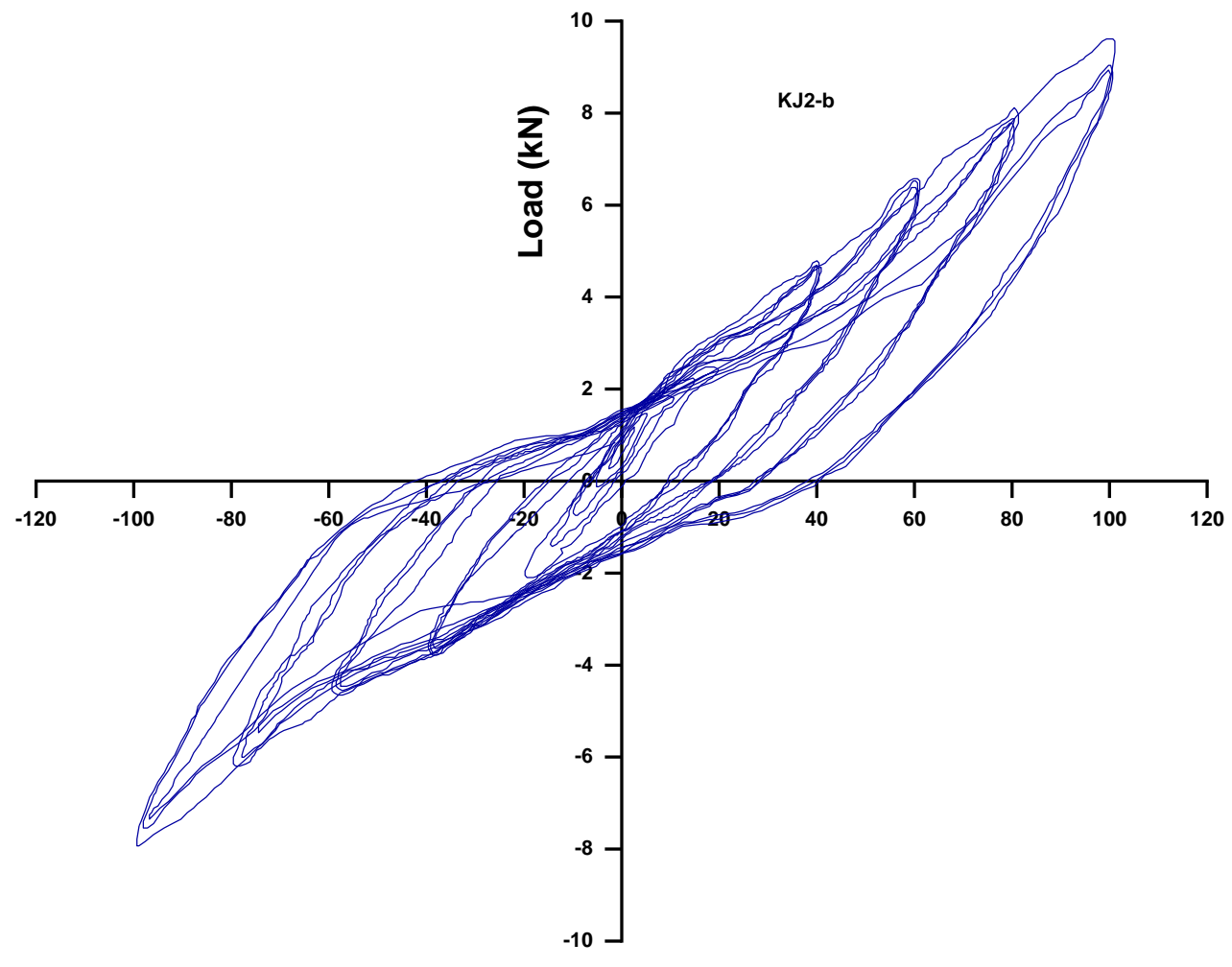

Displacement (mm)

(b) 


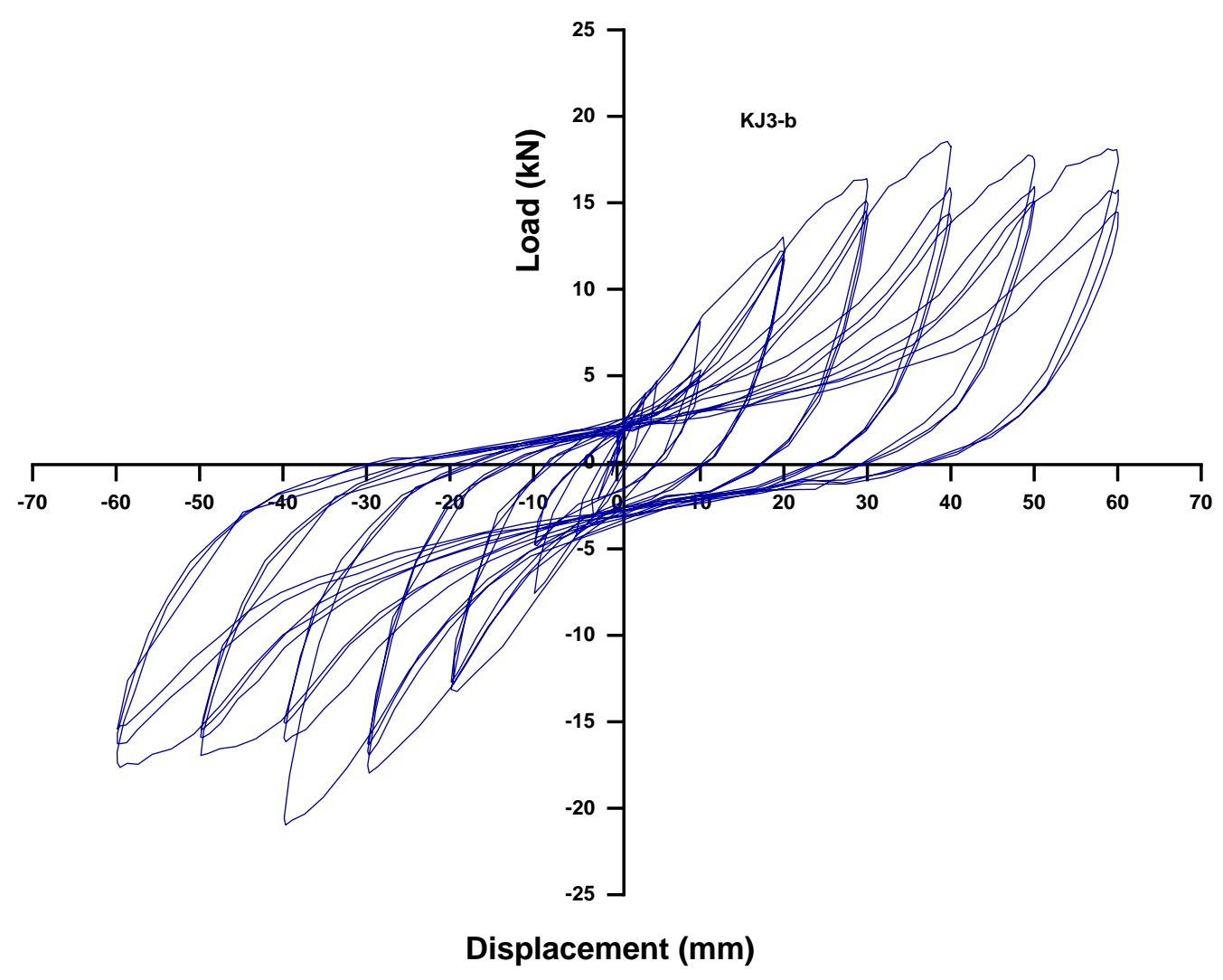

(c)

Fig. 16. Load-displacement curves of three types of specimens under reversed cyclic loading

The ultimate pushing loads had only minor differences, which were reflected in the hysteresis curves of KJ1-b, KJ2-b, and KJ3-b during the same cycle. However, the pushing loads and pulling loads were asymmetric to some extent, and the load under the pulling force was slightly lower that applied by the actuator. Such a difference could have been caused by the loading course. When the tests started, the specimens were first subjected to a positive pushing load. After the pushing load, the poplar LVL timber frame was subjected to the reversed pulling load, which was accompanied by the residual stress caused by the pushing load. Therefore, the reversed load was reduced to some extent.

\section{Envelope curves}

The stiffness, load capacity, energy dissipation, and other properties of the members at different stages of a low-cycle reversed loading test can be determined by analyzing the envelope curves. Figure 17 illustrates the envelope curves of KJ1-b, KJ2-b, and $\mathrm{KJ} 3-\mathrm{b}$.

The envelope curves of specimens KJ1-b and $\mathrm{KJ} 2-\mathrm{b}$ remained at the elastic stage. In comparison, KJ3-b ultimately failed under the low-cycle reversed load after the elastic stage and yield hardening stage. For the bolted steel filling plate connection specimen KJ1$\mathrm{b}$, a gap existed between the steel plate and beam at the initial stage of loading. Thus, the envelope curve could pass through a small slippage stage and gradually turn into an oblique line, and the specimen then entered the elastic stage. According to the comparison of the envelope curves of different specimens, KJ3-b had the highest initial stiffness, and the 
embedment bars connection pure frame specimen KJ2-b had an initial stiffness that was marginally higher than that of the bolted-steel-plate connection in the pure frame specimen $\mathrm{KJ} 1-\mathrm{b}$. The envelope curves of the pure frame specimens KJ1-b and KJ2-b increased slowly at their elastic stages, and the ultimate lateral displacements were far larger than that of the frame-shear wall hybrid structure specimen KJ3-b. Due to the strengthening of the frame by the shear wall, the bearing capacity of KJ3-b was approximately twice as large as that of the pure frame, which indicated the presence of a yield stage after the elastic stage.

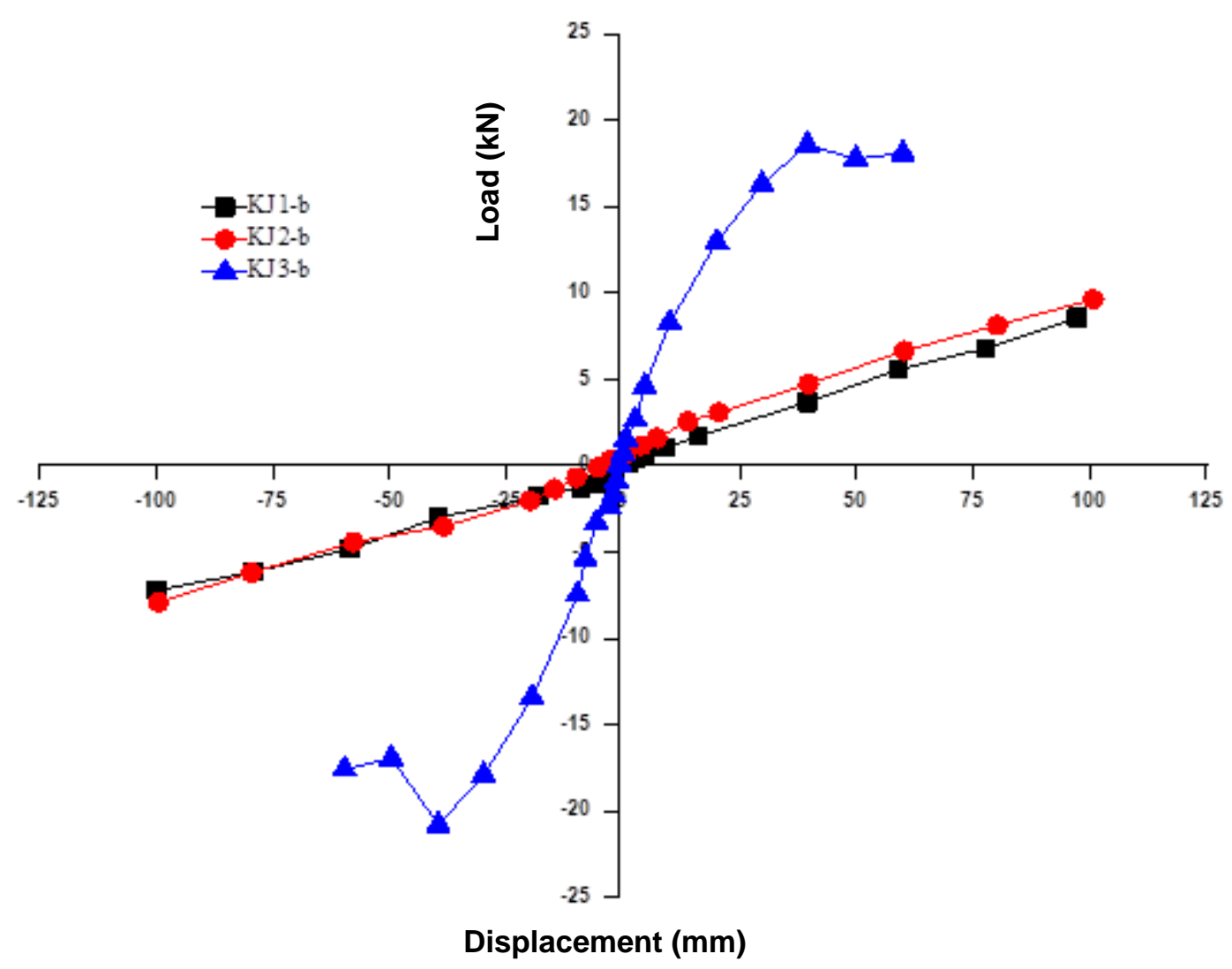

Fig. 17. Skeleton curves of three specimens tested

\section{Stiffness degradation}

The stiffness degradation of the specimens is shown in Fig. 18. Specimen KJ3-b had the highest initial stiffness of $1.77 \mathrm{kN} / \mathrm{mm}$. The stiffness degradation of the hybrid structure shear wall with SPF studs and that of the OSB and plywood sheathing panels reported by Shenton, III et al. (1998) are also shown in Fig. 18 for comparison. The highest initial stiffness of the hybrid structure shear wall with SPF studs and that of the OSB and plywood sheathing panels were $2.34 \mathrm{kN} / \mathrm{mm}$ and $2.28 \mathrm{kN} / \mathrm{mm}$, respectively (Shenton, III et al. 1998). However, as loading displacement gradually increased, they showed larger degradation in stiffness than KJ3-b. Specimen KJ1-b had a non-obvious stiffness degradation with a trend similar to that of $\mathrm{KJ} 2-\mathrm{b}$, and the degradation in stiffness largely remained at the ideal elastic stage as displacement increased. For KJ3-b, the stiffness degradation was obvious during the initial loading stage. As load increased, the shear wall gradually lost bearing capacity. The load was then held by the external frame, and the degradation in stiffness leveled off progressively similar to specimens KJ1-b and KJ2-b. It 
can be found from Fig. 18 that the stiffness of KJ1-b and KJ2-b samples made of LVL frames was relatively small; thus these samples could not be directly used in a structure albeit the degradation of stiffness was not obvious. However, as for KJ3-b sample, the studs and OSB sheathing panels were added to the LVL frame, producing a large increase in stiffness. The comparison of using plywood and OSB as sheathing panels in the samples tested suggested the similar degradation of stiffness. This could be due to (1) The different testing methods. The transferring of load in SPF-PW and SPF-OSB samples was stiff, resulting in the upper limit of test values. The tests conducted in this manuscript adopted the novel loading beam, producing the lower limit of test values (Liu et al. 2008); (2) The different loading schemes. SPF-PW and SPF-OSB samples were tested in accordance with the draft standard for dynamic testing recently proposed by SEAOSC (Shepard 1996). The method used in this study followed the standard ISO-16670 (ISO 2003); and (3) The different test materials used. All these possible reasons could impact the test results to some degree.

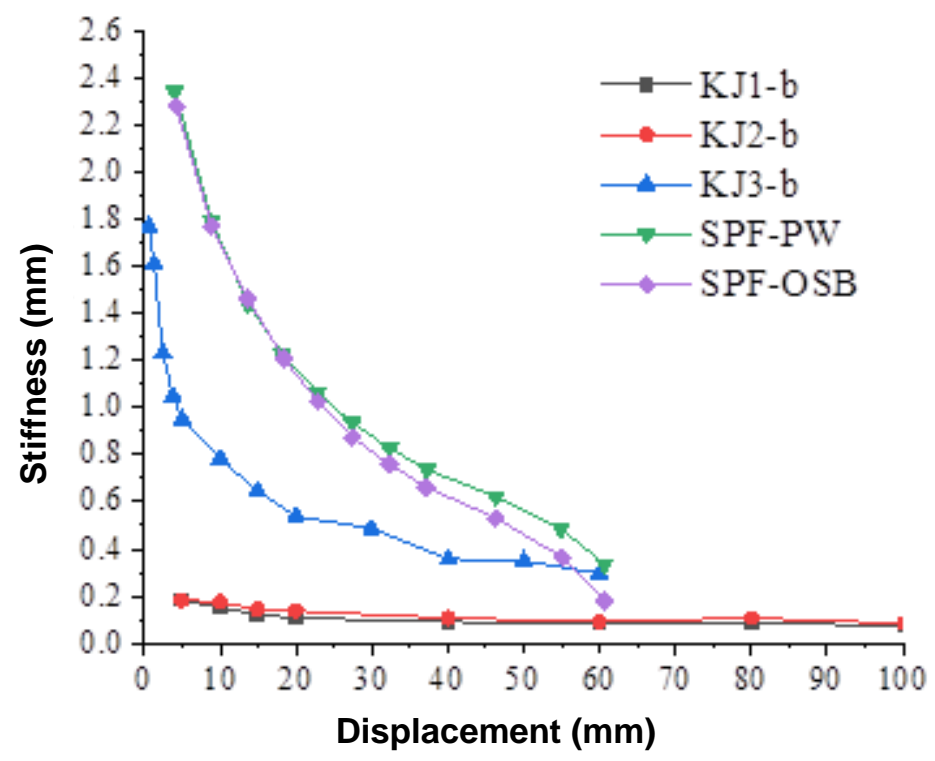

Fig. 18. Stiffness degradation curves of three specimens

\section{Analysis of energy dissipating capacity}

At the various levels of low-cycle reversed loads, the equivalent viscous damping coefficients of all three specimens at each displacement-control cycle are shown in Fig. 19. At the initial loading stage, the equivalent viscous damping factor (EVDF) of the three types of specimens increased to some extent and then decreased as displacement increased. This suggested that the pinch effect of the load-displacement curves became more obvious when the displacements of the structures increased.

The EVDF of KJ1-b increased more obviously at the initial loading stage, dropped drastically when the displacement reached $20 \mathrm{~mm}$, and became stable when the displacement reached $40 \mathrm{~mm}$. The EVDF of KJ2-b increased marginally at the initial loading stage and then dropped evenly after the displacement reached $17 \mathrm{~mm}$. For KJ3-b, the plastic deformation occurred when displacement reached $40 \mathrm{~mm}$ with little change in the damping coefficient, and the EVDF reduced gradually after the failure load. 


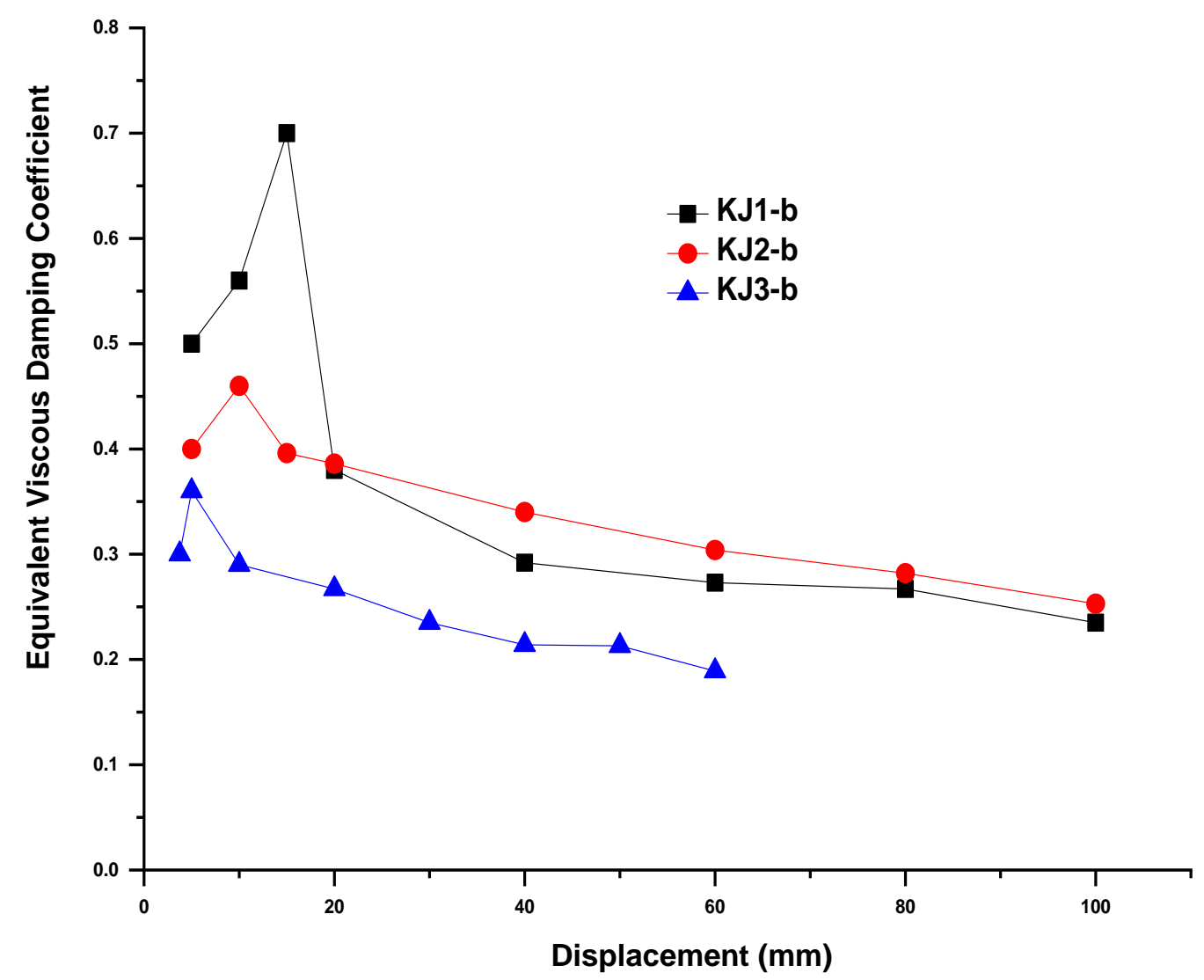

Fig. 19. Equivalent viscous damping factor of three types of specimens tested

In a word, the mechanical properties of the wall samples made of LVL frame could meet the values stipulated in this Chinese standard GB/T 50361-2018 "Technical standard for infills or partitions with timber framework" (GB/T, 2018). This confirms the feasibility of using poplar LVL to make frame-shear wall hybrid structures.

\section{CONCLUSIONS}

1. The ultimate load of frame-shear wall in the hybrid structure specimen was approximately 1.7 times as large as the ultimate bearing capacity of the poplar LVL bolted wood-steel-wood connection in the pure frame. The lateral force resistant stiffness and ultimate loads of the poplar LVL pure frame with bolted steel filling plate connections and closed rod connections were much lower than those of the poplar LVL frame-shear wall hybrid structure. These two connections showed similar performances in poplar LVL pure frame specimens.

2. The highest initial stiffness of the poplar LVL frame-shear wall hybrid structure was $1.77 \mathrm{kN} / \mathrm{mm}$, which was $24 \%$ and $22 \%$ lower than the highest initial stiffness of the hybrid structure shear wall with SPF studs and the OSB and plywood sheathing panels, respectively. The poplar LVL frame-shear wall hybrid structure showed a lower degradation in stiffness than the hybrid structure shear wall with SPF studs and the OSB and plywood sheathing panels.

3. The hybrid frame-shear wall structures made of poplar LVL could meet the 
requirements of Chinese standard. However, in the application of poplar LVL pure frames, the lateral deformation must be controlled by adding diagonal braces or shear walls.

\section{ACKNOWLEDGEMENTS}

The authors sincerely thank the Ministry of Science and Technology (China) for its support under the National Key Research and Development Plan "Green Building and Building Industrialization" (Grant No. 2017YFC0703505). The authors are grateful for the New Brunswick Innovation Research Chair Program of the New Brunswick Innovation Foundation of Canada.

\section{RERERENCES CITED}

ASTM E2126 (2009). "Standard test methods for cyclic (reversed) load test for shear resistance of vertical elements of the lateral force resisting systems for buildings," ATSM International, West Conshohocken, PA, USA.

Editorial Committee of the Wood Structure Design Manual (2005). Wood Structure Design Manual (Third Edition), China Construction Industry Press, Beijing, China. (In Chinese)

Erikson, R. G. (2003). Behavior of Traditional Timber Frame Structures Subjected to Lateral Load, University of Wyoming, Laramie, Wyoming.

Gattesco, N., and Boem, I. (2016). "Stress distribution among sheathing-to-frame nails of timber shear walls related to different base connections: Experimental tests and numerical modelling," Construction and Building Materials 122, 149-162. DOI: 10.1016/j.conbuildmat.2016.06.079

GB 50005 (2017). "Standard for design of timber structures," China Construction Industry Press, Beijing, China.

GB/T 50361 (2018). "Technical standard for infills or partitions with timber framework," China Construction Industry Press, Beijing, China.

ISO 16670 (2003). "Timber structure-joints made with mechanical fasters-Quasi-static reversed cyclic test method," International Organization for Standardization, Geneva, Switzerland.

JGT/T 101 (2015). "Specifications for seismic test of building," China Architecture \& Building Press, Beijing, China. (In Chinese)

Komatsu, K. (2004). "Lateral shear performance of the wooden post and beam structure with prefabricated small mud shear walls," in: Proceedings of the 8th World Conference on Timber Engineering, Vol. 1, Lahti, Finland, pp. 159-164.

Lam, F., Schulte, M., Yao, C. C., and James, J. G. U. (2008). "Moment resistance of bolted timber connection with perpendicular to grain reinforcements," in: Proceedings of the $10^{\text {th }}$ World Conference on Timber Engineering, Miyazaki, Japan, pp. 2-5.

Liu, Y., Ni, C., Lu, W., Lv, X., and Zhou, D. (2008). "Effect of variable upper stiffness on the performance of wood shear walls," China Civil Engineering Journal 41(11), 63-70. DOI: 10.15951/j.tmgcxb.2008.11.012

Liu, Y., Wang, H.-H., Ding, P.-R., and Song, Y.-L. (2017). “The physical mechanical 
properties of poplar LVL," China Forest Products Industry 44(2), 12-16. DOI:

10.19531/j.issn1001-5299201702003

Premrov, M., and Kuhta, M. (2011). Experimental Analysis on Behaviour of Timberframed Walls with Different Types of Sheathing Boards, University of Maribor, Maribor, Slovenia.

Schwendner, S., Seim, W., and Hummel, J. (2018). "Light-frame walls with OSB and GFB sheathing under earthquake impact- a comparative study," in: Proceedings of the $15^{\text {th }}$ World Conference on Timber Engineering, August 20-23, Seoul, Korea.

Shenton, III, H. W., Dinehart, D. W., and Elliott, T. E. (1998). "Stiffness and energy degradation of wood frame shear walls," Canadian Journal of Civil Engineering 25(3), 412-423. DOI: 10.1139/197-108

Shim, K.-B., Kwang, K.-H., Park, J.-S., and Park, M.-J. (2010). "Lateral load resistance of hybrid wall," in: Proceedings of the $11^{\text {th }}$ World Conference on Timber Engineering, Trentino, Italy.

Suzuki, Y., and Maeno, M. (2013). "Structural mechanism of traditional wooden frames by dynamic and static tests," Structural Control and Health Monitoring 13(1), 508522. DOI: $10.1002 /$ stc. 153

Thelandersson, S., and Larsen, H. J. (2003). Timber Engineering, John Wiley \& Sons, Chichester, West Sussex, UK.

White, K. B., Miller, T. H., and Gupta, R. (2010). "Effects of dead load and multiple earthquake loadings on seismic performance of wood-frame shear walls," Forest Products Journal 60(2), 150-156. DOI: 10.13073/0015-7473-60.2.150

Article submitted: May 26, 2020; Peer review completed: June 29, 2020; Revised version received and accepted: November 10, 2020; Published: November 18, 2020.

DOI: 10.15376/biores.16.1.354-371 